\title{
COMENTARIO LITERARIO Y LECTURA PSICOANALÍTICA DE LA GRADIVA EN JENSEN Y FREUD
}

\section{A LITERARY AND PSYCHOANALYTIC READING OF JENSEN AND FREUD'S GRADIVA}

\author{
Marina Aguilar Salinas ${ }^{1}$ \\ Universidad de París
}

Recibido: 15/ 8/ 16

Aceptado: 8/ 11/ 16

Resumen: La lectura que propone Freud de Gradiva, la obra de Wilhelm Jensen, es el punto de partida de este artículo, donde se quiere poner especial atención en la singularidad de un sí mismo que, en ocasiones, confunde sueño con realidad. El amor es un terreno propicio para el encuentro con la alteridad. En el encuentro amoroso, dos sí mismos conversan y uno se deja caer en el otro. Es el caso del protagonista de Jensen, enamorado que se deja caer. Ese abandono es el motor de la cura de su delirio.

Palabras clave: Gradiva, Freud, Jensen, humano, alteridad, viaje, encuentro amoroso, delirio, sueño, realidad, singularidad.

\begin{abstract}
Freud's reading of Gradiva, where he works on the character of Wilhelm Jensen, is the point of departure for this article which accentuates the singularity of a 'oneself' which sometimes confuses dreaming, delirium and reality. Love, here, is depicted as a fertile terrain for an encounter with otherness. In such a romantic coupling, two one-selves conduct a dialogue and one of them lets go of the other, namely the principal lover Jensen. This abandonment turns out to be the driving force behind the cure of his delirium.
\end{abstract}

Keywords: Gradiva, Freud, Jensen, human, otherness, voyage, love, delirium, dream, reality, singularity.

1. (marina.aguilar.salinas@gmail.com) Terminó el Máster de Psicoanálisis en junio de 2016 en la Universidad de París 8 Vincennes Saint-Denis. También realizó un Máster de Filosofía en la Universidad de Lyon 3 Jean Moulin. 
La pregunta por lo humano puede resultar golosa, pero también es fuente de dificultades, ya que este adjetivo sustantivado indica algo general y entiende lo general por oposición a ciertas excepciones que excluye de su perímetro. Un modo clásico de generalizar es el que hace uso del cuantificador lógico proponiendo juicios universales afirmativos: «Todo S es P». Tal vez el sentido común deja intuir que lo humano no está necesariamente involucrado en este tipo de juicios, porque el terreno de estos juicios es la lógica de predicados. La excepción de este sistema procedería, por ejemplo, de un universal negado y mezclado con un particular. La fórmula «No todo $\mathrm{S}$ es $\mathrm{P}$ », que no aparece en el cuadrado aristotélico, tiene algo del juicio indefinido: «algunos S no son P», pero se enuncia de otro modo.

Si pudiésemos incluir tal sustantivación dentro de un predicado aristotélico, no usaríamos para ello un juicio universal como el de «Todo $\mathrm{S}$ es P», sino más bien una posición excepcional ligada al «No todo S es P». Lo humano suele presumir de una genuina singularidad y dicha presunción acecha cuando se habla de lo humano. Lo humano presume de que no hay humano que sea igual a otro. Podríamos decir que lo humano es un falso amigo, pues invita a pensar una totalidad universal sin que al mismo tiempo se olvide que cada núcleo simple, cada individuo, tiene algo de abismático. Lo singular vigila a la definición, la mira de reojo con la esperanza de alterar la supuesta consistencia que ésta pudiera tener.

La ficción, y dentro de ella, la literaria, que tiene algo de desecho, de litter $^{2}$, como decía medio en broma Lewis Carroll, suele ser un modo de singularización de lo humano, porque no hay una ficción que sea igual a otra y hasta un ágrafo -tal vez incluso más que el resto- se da cuenta de eso. De tal manera, lo extremadamente singular se singulariza aún más en literatura o en litteratura, si aplicamos el juego de palabras del matemático inglés. Lo que siempre fue singular y permaneció oculto tras un velo de invisibilidad, eso reluce en la litteratura.

Desde el comienzo, este artículo relata cómo Sigmund Freud, llevado por su interés por el psicoanálisis, estudia la ficción de Jensen con el fin de aclarar el fenómeno que Freud nombra delirio. El analista encuentra en la ficción literaria un lugar privilegiado para la lógica del inconsciente,

2. Carroll, L.: Silvia y Bruno, AKAL, 2013, traducción de Axel Alonso Valle. En el prólogo, Lewis Carroll utiliza jocosamente la palabra litterature, una mezcla inventada entre litter (basura) y literature. Más tarde, Lacan lo rescata en su texto Lituraterre, más interesado en el uso lúdico de la lengua que en la literatura como texto académico y normativo. "La civilización es la basura", dice Lacan, tras usar el litter de Carroll. Lacan quiere señalar un goce que aparece ligado a la sonoridad que se desprende del lenguaje literario, cuando se usa de cierto modo. La sonoridad de la lengua inglesa permite toda clase de equívocos y juegos de doble sentido, algo que en otros idiomas ocurre de otro modo.

Thémata. Revista de Filosofía N55 (2017) pp.: 287-302. 
sin que tal privilegio le lleve a formular leyes generales. Lo humano, tan difícil de atrapar, tan abismático, residiría entonces en la singularidad con que cada uno aborda el trocito de ficción que le toca.

\section{2}

En el año 1901, Wilhelm Jensen publica una novela que pasa a la historia gracias al reconocimiento posterior que le otorga Freud en un texto publicado unos años después, en $1907,{ }^{3}$ y que recoge el original sumándole además algunos comentarios. Así, Freud propone una interpretación psicoanalítica de la obra. Bajo esta doble publicación de Jensen y de Freud, la obra de Jensen aparece como fruto de la reconstrucción del psicoanalista, quien justo antes de esa fecha publica La interpretación de los sueños ${ }^{4}$. Freud ofrece, no sin advertir que lo mejor es ir al original, una breve interpretación de la obra de Jensen, que se enmarca dentro de su primer período y que dista de lo que más adelante, en 1920, acuña como pulsión de muerte.

\section{3}

El protagonista de la historia de Wilhelm Jensen es Norbert Hanold, un joven alemán apasionado de la arqueología y nada atraído por las chicas ni por el amor. Este joven de espíritu soñador y distraído encuentra un día un bajorrelieve romano que representa la figura de una muchacha desplazándose con el pie ligeramente levantado, en un gesto de suma delicadeza. Dicha imagen es la de Gradiva, la que avanza, imagen de una pompeyana del año 79 d.C. Norbert se obsesiona tanto con la imagen que sale a la calle a verificar, ante el asombro de todos, si alguna de las mujeres de su entorno anda parecido o si, por el contrario, el andar de Gradiva es único.

Su obsesión crece a pasos agigantados y pronto sueña con Gradiva, joven habitante de Pompeya. Los elementos reales y fantásticos se confunden hasta que ni Norbert ni el lector saben si lo que aquél vive es soñado, real o fruto de una fantasía tan vívida que despunta en un elaborado delirio. Ahora bien, ¿en qué consiste dicho delirio? El psicoanálisis freudiano concibe el delirio como una elaboración que surge en el sujeto en respuesta a un punto de no retorno, inexplicable, que causa en él perplejidad. Ante

3. Freud, S.: Obras Completas, vol. 9, El delirio y los sueños en la "Gradiva" de W. Jensen y otras obras (1906-1908), Buenos Aires-Madrid, Amorrortu Editores, 2007.

4. Freud, S.: Obras Completas, vol. 4 y 5, La interpretación de los sueños (primera y segunda parte), Buenos Aires-Madrid, Amorrortu Editores, 2007-2010.

Thémata. Revista de Filosofía $\mathrm{N}^{\circ} 55$ (2017) pp.: 287-302. 
esa perplejidad, el sujeto produce un delirio y dicha producción es tanto una respuesta como un intento de cura. El delirio va tomando distintos elementos y va uniéndolos hasta formar un conjunto más o menos estructurado que explica algo, da razón de algo. Contiene un orden lógico.

Así, conducido por la extraña impresión que le produce la visión de un canario enjaulado, Norbert emprende un viaje a Pompeya. En su camino encuentra parejas de enamorados por los que siente desprecio y repugnancia. Él sólo persigue a Gradiva, pero, en su persecución, es incapaz de reconocer ninguno de los sentimientos amorosos que ve en sus semejantes.

Para su sorpresa, Norbert encuentra a Gradiva en las calles de Pompeya, donde todo parece volver a la vida del año 79 d.C., un día, al mediodía. También asombrada, Zoe le responde en alemán y le sigue el juego, desmontando una a una sus verdades delirantes sobre Pompeya y sobre sí misma, Gradiva a los ojos de Norbert, vuelta a la vida tras haber muerto un día bajo la lava en Pompeya, espectro de aquellos años que camina y cuyo cuerpo es de naturaleza dudosa. La conversación con Zoe ayuda a que la frontera entre imaginación y realidad se reestructure. Gradiva resulta ser una elaboración fantasiosa de Norbert a partir de la figura de Zoe, su vecina y compañera de juegos de la infancia, quien, debido a la indiferencia de su padre, más ocupado en la zoología que en ella, había encontrado en Norbert a un compañero a quien amar incondicionalmente y sustituto del amor que ella sentía por su padre. Cuando ve que Norbert Hanold la ha incluido en su propia historia delirante, decide seguirle el juego y, al mismo tiempo, sacarlo poco a poco de él.

Tras la conversación entre los dos personajes, todos los datos se van ordenando, los misterios y enigmas resolviéndose y el delirio desmontándose con ayuda de algunas aclaraciones que surgen en la conversación de Norbert y Zoe. Así, el contenido del delirio se descifra como una serie de mensajes olvidados o transformados. Una vez desvelado su sentido amoroso, la creencia de Hanold en su delirio se desvanece.

Freud ve en Norbert Hanold a un personaje poderosamente atraido por los pies de Gradiva, "la que avanza», que aparecen esculpidos y desnudos -sólo recubierto el talón por unas sandalias- en esta misteriosa representación. Alrededor de dicha figura, se pone en juego una confusión básica: la que existe entre un delirio (que es una construcción elaborada y lógica, ya que es explicativa, como el delirio de Schreber $^{5}$ ) y los sueños. Dicha confusión genera importantes implicaciones clínicas para Freud. Una lectura superficial del relato ve en el detalle del pie una clara alusión al fetichismo. Dos imágenes fundan el relato: un bajorrelieve que representa a una chica y el pie en movimiento de dicha representación. Ambas

5.Schreber, P.: Memorias de un enfermo de nervios.

Thémata. Revista de Filosofía N55 (2017) pp.: 287-302. 
producen en Norbert «una vivísima fantasía, que no sólo en sueños, sino hasta en la vigilia, solía arrebatarlo». ${ }^{6}$ La psiquiatría tradicional diría que Norbert es fetichista, pero ese rasgo indica sólo que Norbert desea a Zoe y que el objeto de su deseo se cristaliza y se hace visible en el andar. Este rasgo es, por lo tanto, un señuelo de su verdadero diagnóstico. Además, el pie de la chica se muestra sólo fugazmente y en constante movimiento. Ya no es el pie, sino su imagen, huidiza, inmaterial, lo que ve el protagonista, Norbert Hanold, sin saber si eso que ve-aquel bajorrelieve materializado en una chica de carne y hueso- es sueño o realidad. Esta visión del modo de caminar fomenta el deseo de Hanold por Gradiva, figura que eleva a la altura de un ídolo de la antigua ciudad de Pompeya y que lo traslada a la ciudad en busca de su amada.

El relato se construye también alrededor del tópico del viaje. Norbert, tras la simbólica y aparentemente banal observación, en algún lugar desconocido, del mencionado canario, emprende su viaje. En su recorrido, el encuentro con las parejas de enamorados lo deja agotado. Las visiones y la confusión entre sueño y realidad aumentan: «Su insatisfacción no nacía sólo de lo que hallaba en su entorno; en parte, brotaba de él mismo». ${ }^{7}$

Tras su llegada a Pompeya, el viaje adquiere un nuevo sentido más transcendente, de viaje entre la vida y la muerte, entre dos mundos, entre el olvido y el recuerdo. Una vez en Pompeya, la confusión es mayor y al mediodía la ciudad entera parece recobrar vida. En aquel escenario, Norbert, de repente, ve a Gradiva, a quien ya había visto en sueños y, por supuesto, en su bajorrelieve. ${ }^{8}$ Fascinado, le habla, primero en griego, luego en latín. Ella contesta que si quiere hablar con ella deberá hacerlo en alemán. La primera respuesta de Zoe a Norbert es un principio de realidad, que lo traslada lejos de su ensoñación pompeyana: habla alemán, como él.

Tanto Jensen como Freud conceden un carácter fantástico a los personajes, esto es, sin ninguna referencia en el plano real. No obstante, ello no impide que dichos personajes reflejen algo de la vida psíquica. El motor del relato es el encuentro amoroso. Todo gira en torno al encuentro entre Norbert y Zoe, en la niñez y en la juventud, en el sueño y en el delirio ${ }^{9}$. El inconsciente y sus mecanismos de censura se encargan de reprimir todo lo relativo al encuentro amoroso, ya que éste contiene algo muy

6. Freud, S.: El delirio y los sueños en la «Gradiva» de Jensen, Op. cit., p. 13

7. Ibid., p. 14

8. Ibid., p. 15

9. En 1907 ya habían pasado siete años desde la publicación de La interpretación de los sueños. Posiblemente quisiera comparar el sueño, cuya tesis principal en 1900 es que el sueño representa el cumplimiento del deseo, (en 1920, el concepto de pulsión de muerte dará al traste con esa visión) con el delirio. Eso permitiría una taxonomía que ayudaría a una mejor distinción de estos conceptos fundamentales.

Thémata. Revista de Filosofía N55 (2017) pp.: 287-302. 
censurable y ligado a la sexualidad, pero es inevitable que dicho contenido encuentre otra vía de escape: « (...) el azar espeja la fatalidad que ha ordenado reencontrarse, justamente por medio del instrumento de la huida, con aquello de lo que se huye». ${ }^{10}$

\section{4}

La cuestión de si lo que Norbert experimenta es o no un delirio, es decir, si el relato pertenece o no a la literatura fantástica, es un asunto central en el relato y se resuelve, si bien el autor mantiene al lector en la tensión de la perplejidad, jugando con su creencia en su carácter fantástico. Hay dos posibilidades: o bien Norbert delira, o bien todo forma parte de un mundo fantástico cuyo sentido viene dado por la interpretación que Norbert da del mundo. Sin embargo, la segunda hipótesis es menos consistente, ya que el encuentro con Zoe pone al descubierto una doble lectura, la delirante y la real. No obstante, ambas aproximaciones, el delirio y la fantasía de la ensoñación, se ven forzadas a coexistir en el relato.

Frente a la elaboración del delirio, Zoe se sirve de sus argucias para acompañar a Norbert en dicho delirio hasta, mediante un movimiento inverso, sacarlo de él. Freud ve en esta novela un modelo de cura - "...) de qué manera se cura un delirio como el de nuestro héroe» ${ }^{11}$ - parecido al que promueve él desde el psicoanálisis. El delirante debe ser acompañado en su construcción para que sea más fácil escapar de ella. Dicho de otro modo, la cura del delirio debe primero reconocerlo, nunca negarlo. Este movimiento equivaldría a la afirmación de la afirmación delirante, que engendraría una negación de lo que se afirma doblemente:

Es manifiesto que ella entra en su delirio, cuyo alcance total le sonsaca, sin contradecirlo. En una sola ocasión un afecto propio parece arrancarla de su papel: cuando él, pensando en su imagen del bajorrelieve, asevera haberla reconocido a la primera mirada. ${ }^{12}$

Zoe, que significa en griego «vida», aglutina en una misma imagen a dos seres: el bajorrelieve que ha cobrado vida y una chica que Norbert había conocido en su infancia en su ciudad natal. La primera habla latín, la segunda, alemán, y Norbert no repara en su existencia hasta que ésta lo dice.

Debido a la confusión entre sueño y realidad, el delirio ocupa un puesto fundamental en la lectura que hará Freud del relato de Jensen. Según esta lectura, el delirio, de un lado, es un modo de curación ante una

10. Ibid., p. 36.

11. Ibid., p. 19.

12. Ibid., p. 18

Thémata. Revista de Filosofía $\mathrm{N}^{\circ} 55$ (2017) pp.: 287-302. 
vivencia demasiado traumática y, de otro, dicho fenómeno se cura gracias a un encuentro amoroso. El punto de partida del psicoanálisis es similar: la transferencia es un dispositivo basado en una serie de relaciones afectivas que teje el paciente con el analista en base a un sistema de demanda y respuesta. Se parece a un encuentro amoroso, si bien tiene otros matices...

En el comentario de Freud a la obra de Jensen aparece un lazo nodal entre poesía y psiquiatría; Freud asegura que hay una relación necesaria entre $\operatorname{ambas}^{13} \mathrm{y}$ que esta última no debe ocuparse solamente de los estados patológicos extremos, sino de cada pequeña alteración psíquica, de cada pequeña manifestación anímica. La posición de Freud al respecto es clara: la poesía antecede al psicoanálisis. La poesía trata con una lucidez extraordinaria cuestiones que sólo a posteriori son abordadas por los estudiosos de la mente: «En esta polémica sobre la apreciación del sueño, sólo los poetas parecen situarse del mismo lado que los antiguos, que el pueblo supersticioso y que el autor de La interpretación de los sueños». ${ }^{14}$

Igualmente, el concepto de delirio liga poesía y psicoanálisis. ${ }^{15} \mathrm{El}$ propio Jensen utiliza este término. Freud precisa algunos rasgos: el delirio es anímico, no corporal. Esto consiste en que unas cuantas "fantasías" se vuelven predominantes. ${ }^{16} \mathrm{El}$ delirio se forma a partir de la relación entre inconsciente y represión, igual que el sueño: «De ese mismísimo modo se comportan también los enfermos a quienes se les ha aflojado la compulsión de sus pensamientos delirantes revelándoles lo reprimido que tras ellos se esconde». ${ }^{17}$

Freud toma el ejemplo de Jensen con el fin de aclarar algo del inconsciente, apuntando especialmente a dos vértices: el encuentro con Gradiva y la cura del delirio. El delirio está directamente relacionado con el sueño en la medida en que ambos participan de un olvido ${ }^{18}$. En ambos hay una confusión entre el principio de realidad y el principio de placer. Ambos tienden hacia el punto esencial del relato de Jensen: «un bajorrelieve lo atrae con exclusión de cualquier otra cosa». ${ }^{19}$ A partir del encuentro con Zoe, la idea de la unión amorosa deja de tener las connotaciones negativas que habían tenido a lo largo de todo su viaje por Italia y de toda la

13. Ibid., p. 37.

14. Ibid., p. 8.

15. Ibid., p. 38.

16. Ibid., p. 38.

17. Ibid., p. 32 .

18. La represión consiste precisamente en el olvido de un contenido que la conciencia considera demasiado insoportable. Dicho contenido es alojado en el inconsciente. Con el delirio puede resurgir lo reprimido. Sin embargo, hay en la teoría de Freud otros olvidos más fuertes que el de la represión. De este modo, el vienés explicará la psicosis con otro olvido, mayor que el de la represión que dará lugar a una negación mucho más fuerte.

19. Ibid., p. 10.

Thémata. Revista de Filosofía $\mathrm{N}^{\circ} 55$ (2017) pp.: 287-302. 
novela en general. ${ }^{20}$ Norbert da un rodeo hasta recordar a Zoe. Este rodeo también pretende eximirlo de su sexualidad. Así se zafa de lo sexual de su encuentro amoroso. De niños, dicho encuentro no incluía explícitamente la sexualidad. Sin embargo, de adultos, dicha sexualidad aflora con mayor violencia. Sólo a través de la dulzura de la conversación con Zoe, Norbert consigue soltar el lastre de su olvido, deshilachar su elaboración delirante, descomponerlo en trozos y sanar de su necesidad de interpretar.

Finalmente, el delirio es sepultado por el encuentro amoroso, el cual supone un principio de realidad, ya que Zoe, punto nodal de la culminación de su delirio, lo conduce hacia fuera de éste. Esto supone un punto externo a su ensimismamiento, dándole referencias de un mundo que escapa a la consistencia de su interpretación. Su construcción se deshace y Norbert no puede garantizar su veracidad por más tiempo.

Ahora bien, «el triunfo del erotismo» no supone en ningún caso una negación del delirio, pues éste contenía a su vez una carga importante de erotismo. En cambio, en ambos tiene lugar un proceso paralelo. El delirio es un símbolo de la represión de Norbert, represión directamente ligada a lo sexual. ${ }^{21}$ Enterrar lo sexual y amoroso -el olvido de Zoe- implica que lo enterrado permanece vivo. ${ }^{22}$ Pompeya también fue una ciudad enterrada. Norbert es un joven arqueólogo, le gustan las ruinas y los fósiles, lo muerto y lo que habla desde el sueño. Todo en su vida parece estar inspirado por su gusto por el olvido.

Freud asegura que su único propósito ${ }^{23}$ era analizar algunos sueños del relato de Jensen. Sin embargo, su estudio se ha ido ampliando hasta que, finalmente, se ha visto obligado a interpretar los entresijos anímicos de los personajes. El interés psicoanalítico de esta obra ha ido aumentando en el curso de su lectura. En efecto, durante el análisis ocurre algo similar a lo que ocurre con los personajes del relato de Jensen. Sin embargo, para comprender esto, se recomienda examinar la trayectoria del paciente, así como otras manifestaciones de su posición inconsciente. En otras palabras, un sueño aislado no dice nada, sino que hay que reconstruir la trayectoria del que sueña y, al mismo tiempo, reconstruir el sueño si queremos abordarlo desde la técnica de la interpretación de los sueños.

Una serie de fantasías oníricas fundan la construcción delirante de Norbert. Éstas sirven para camuflar ciertos contenidos a los cuales el

20. Ibid., p. 22.

21. Ibid., p. 33. Esto coincide con la primera fase del desarrollo de la tópica freudiana, donde el inconsciente se interpreta siguiendo las pistas de lo sexual reprimido.

22. Ibid., p. 34.

23. Sin embargo, fue Jung quien vio por primera vez en La Gradiva una obra interesante para interpretarla desde la teoría de los sueños de Freud. Ibid., p. 9.

Thémata. Revista de Filosofía N55 (2017) pp.: 287-302. 
sujeto opone resistencia: ${ }^{24}$ "El andar de Gradiva no se registraba en la realidad ${ }^{25}$ En particular, el delirio de Norbert toma fuerza gracias a algunos sueños relacionados con Gradiva: en el primero, Norbert vive en la misma ciudad y tiempo que la mujer buscada, ${ }^{26}$ en Pompeya en el año 79. Este sueño es según Freud un "sueño de angustia», ${ }^{27}$ pero dicha angustia traduce la libido sexual reprimida. La represión de la excitación del afecto sexual da lugar a sueños de angustia, así como a sustituciones del contenido reprimido por otros contenidos que favorecen el delirio. De esta manera, "sueño y delirio proceden de la misma fuente: lo reprimido». ${ }^{28}$ Esta idea coincidiría con la tesis general de La interpretación de los sueños, que indica que «el sueño figura un deseo como cumplido». ${ }^{29}$ En otro sueño Hanold entremezcla algunos elementos del día anterior con su objeto de amor, Gradiva, cazando una lagartija. También aparece un pájaro. Todos son animales simbólicos que tienen que ver con el padre de Zoe, -zoólogo más centrado en su vocación que en su hija- con su casa y con los recuerdos reprimidos de Hanold durante su infancia compartida. ${ }^{30}$

La idea central del texto de Freud es que existe un vínculo insoslayable entre el sueño y el delirio. El primero tiene lugar todas las noches cuando las resistencias se relajan, mientras que el segundo ocurre en casos puntuales, con la elaboración de ciertas fantasías frente a ciertos contenidos reprimidos. Ambas manifestaciones del inconsciente contienen "un granito de verdad» ${ }^{31}$, es decir, hay un nudo en el centro de la elaboración del entramado delirante. Dicha creencia ha sido censurada, dando lugar a lo «erróneo consciente». ${ }^{32}$

La comunicación entre Zoe y Norbert está plagada de equívocos y de juegos de palabras donde el doble sentido ${ }^{33}$ lleva a la consciencia lo que antes permanecía inconsciente: «Me parece como si ya una vez, hace dos mil años, hubiéramos comido así juntos nuestro pan. ¿No puedes acordarte?». ${ }^{34}$ Zoe se hace partícipe de las ensoñaciones de Norbert con bellas metáforas de su niñez, jugando al juego de haber sido amigos en el año 79 d.C. Su encuentro produce un cambio en la formación delirante de Norbert

24. Ibid., pp. 48, 49, 50.

25. Ibid., p. 11.

26. Ibid., p. 48.

27. Ibid., p. 50. Freud, S.: La interpretación de los sueños, (Segunda parte) Op. cit., p. 565.

28. Freud, S.: El delirio y los sueños en la "Gradiva" de Jensen, Op. cit., p. 52.

29. Freud, S.: La interpretación de los sueños, Vol. 4, Op. cit., p. 143.

30. Freud, S.: El delirio y los sueños en la «Gradiva» de Jensen, Op. cit., p. 61.

31. Ibid., p. 67.

32. Ibid.

33. Ibid., p. 70.

34. Ibid., p. 71.

Thémata. Revista de Filosofía $\mathrm{N}^{\circ} 55$ (2017) pp.: 287-302. 
y marca el inicio de una cura progresiva, debido a que Zoe acepta el doble juego de los equívocos y los mensajes ocultos. Su entrada en el delirio de Norbert introduce, paradójicamente, un punto de apoyo para salir de él. Es como si al jugar con la verdad de Norbert, ella contribuyese a poner en duda dicha verdad. Como si su mirada, su participación, al no ser la misma que la de él, introdujese una alteridad necesaria para sacarlo de su ensimismamiento. Por su parte, Zoe también siente curiosidad por desentrañar el contenido del delirio y por saber en qué medida la ha incluido él en su historia, ya que ella también lo ha incluido a él en la suya. El delirio de Norbert es, por tanto, tomado por Zoe como signo de amor.

Jensen enlaza el final del delirio con el triunfo del amor en un happy ending, pero para Freud lo importante no es el final, sino el principio, el encuentro amoroso. El amor es un mecanismo de curación similar al de la transferencia. ${ }^{35}$ La psiconeurosis de la que sería partícipe Hanold tiene como causa la represión de un fragmento de la vida pulsional y sexual. Ese tipo de amor que es el psicoanálisis da libertad al contenido inconsciente reprimido que aflora penosamente. ${ }^{36}$ Es, en cierto modo, una cura por medio del amor. Jensen ilustraría avant-la-lettre lo que Freud teorizó para su práctica psicoanalítica.

A pesar de su vinculación, la poesía no ofrece la misma explicación que el psicoanálisis. Más bien desmiente toda explicación causal de los fenómenos. Al contrario que el médico, el poeta no busca causas o explicaciones racionales para los fenómenos. Sin embargo, algo une la figura del poeta y la del psicoanalista: el inconsciente. A diferencia del segundo, el primero no necesita descifrarlo, sino que trata con él con fines productivos.

Por último, Freud reafirma su tesis sobre la interpretación de los sueños: «el sueño es deseo que se figura como cumplido». ${ }^{37}$ Gradiva soñada es Zoe deseada. Sin embargo, esta tesis tiene sus límites: no todos los sueños albergan un deseo reprimido ni se interpretan en función de su desciframiento. El ombligo del sueño ${ }^{38}$ (punto ciego que señala lo desconocido e imposible de representar del sueño) y la pulsión de muerte ${ }^{39}$ (pulsión repetitiva, de desintegración, más allá de la búsqueda de satisfacción) van más allá de esa satisfacción y no persiguen el objeto deseado, sino una

35. Ibid., p. 73.

36. Ibid., p. 74.

37. Freud, S.: La interpretación de los sueños (Primera parte), Op. cit., p. 143.

Freud, S.: La interpretación de los sueños (Segunda parte), Op. cit., p. 543.

38. Ibid., (519) «Aun en los sueños mejor interpretados es preciso a menudo dejar un lugar en sombras, porque en la interpretación se observa que de ahí arranca una madeja de pensamientos oníricos que no se dejan desenredar, pero que tampoco han hecho otras contribuciones al contenido del sueño. Entonces ése es el ombligo del sueño, el lugar en que él se asienta en lo no conocido». 39. Freud, S.: «Más allá del principio de placer, Psicología de las masas y análisis del yo, y otras obras», Obras Completas, vol. 18 (1920-1922) Amorrortu Editores, Madrid, 2008.

Thémata. Revista de Filosofía $\mathrm{N}^{\circ} 55$ (2017) pp.: 287-302. 
repetición pulsional donde nada se satisface y que carece de telos, ya sea consciente o inconsciente.

\section{5}

Finalmente, lo humano hace mella en lo universal, contribuyendo al decaimiento de las leyes generales. Se ha dicho frecuentemente que Freud describe a un ser humano pesimista, atormentado por su superyó, condicionado por sus neurosis. No obstante, la reflexión freudiana afirma hasta la última consecuencia la división del sujeto. Esto no es necesariamente algo negativo, pero sí está ligado al vínculo entre el sujeto y el lenguaje y, por ende, al vínculo de ambos con la ficción. Lo que aquí se sostiene es que la mente no forma una unidad, sino que está dividida en partes y que dichas partes son inconciliables entre sí.

Enmarcado dentro del pensamiento de la sospecha y reacio a cualquier modo de objetivar y escribir la totalidad de lo que sucede, reacio en definitiva a la ciencia positiva, el pensamiento freudiano reconoce las limitaciones de la razón y no sólo, sino además el hecho de que la razón surge a raíz de una división que no es para nada racional. Al hilo de esta visión, encontramos también en Nietzsche en el epígrafe 111 de La Gaya Ciencia una tesis que relaciona directamente el origen de la lógica con una tendencia profundamente ilógica y sin sentido. ${ }^{40} \mathrm{El}$ estrecho vínculo entre la lógica y lo ilógico distaría desde esta perspectiva nietzscheana del cuantificador universal afirmativo de los juicios aristotélicos. El juicio global no sería posible, ya que la lógica tendría un origen ilógico. Desde este punto de vista desde el cual la lógica se nutre de lo que es contrario a ella, lo humano no se correspondería con lo general o lo universal. En el mismo epígrafe, Nietzsche critica profundamente la noción de sustancia y dice que dicha noción no se corresponde con nada de lo real en sentido estricto. ${ }^{41}$

El ser humano que describe Freud, si es que acaso describe alguno de manera global, está dividido en una serie apartados incompatibles. Esta división recuerda un poco al pasaje de Fedro donde Platón alude a la alegoría del carro alado. El auriga tendría que vérselas, al igual que el sujeto dividido con varios compartimentos muy poco compatibles entre sí. Ante la incertidumbre y la ausencia de unidad no existe solución; sólo queda dirigir el carro. Las almas como el auriga, están sometidas a una

40. Nietzsche, F.: Le gai savoir, Folio Essais, 1982, traducido del alemán por Pierre Klossowski, p. 141. (Epígrafe 111) [u.] t.

Nietzsche, F.: La gaya ciencia, AKAL, 2001, Epígrafe 111.

41. Ibid.

Thémata. Revista de Filosofía $\mathrm{N}^{\circ} 55$ (2017) pp.: 287-302. 
constante lucha entre sus distintas partes y es el auriga quien debe, con algo de lucidez, evitar que un caballo tome las riendas más de lo debido, ya que, en los seres que no son dioses, las razas de los aurigas y de los caballos están mezcladas, y no son del todo buenas ni puras. Uno de los caballos es bello y bueno, mientras que el otro es «lo contrario de éste. De ahí que por necesidad sea difícil y adversa la construcción de nuestro carro» ${ }^{42}$. La dificultad radica en el riesgo que implica la inclinación hacia el mal, el lado perverso de los transcendentales, lo falso, lo feo, lo malo. «El corcel que participa de maldad es pesado, gravita hacia la tierra, y entorpece a los cocheros que no estén bien entrenados» ${ }^{43}$.

A lo largo de la teoría psicoanalítica de Freud se advierte una clara herencia del platonismo. Es de sobra conocido su recurso a la Grecia clásica para construir sus mitos antropológicos. Siguiendo esta línea, el teórico se inspira igualmente en algunos elementos que encontramos en textos y pasajes fundamentales del discípulo de Sócrates $^{44}$.

Por otra parte, la transferencia, dispositivo analítico por excelencia, cuenta con claros referentes platónicos. La transferencia es el modo por el cual el sujeto en análisis establece una relación amorosa con el analista, al que supone un saber que le concierne y que concierne también la posición propia respecto de su deseo. El «qué quiero con mi vida, conmigo», reversible junto con el "qué quieren los otros de mí», se plantea en el proceso de la transferencia, que no es sino la posibilidad de transferir por la vía de la palabra una serie de creencias, saberes, no saberes y deseos al analista. $\mathrm{Al}$ comienzo, todo esto está muy desordenado. El Banquete ${ }^{45}$ y lo que de él extraemos sobre el amor, es uno de los puntos de entrada platónicos en lo que Freud desarrollará en la práctica analítica con la transferencia. Pero hay más: todo el sistema dialógico de Platón tiene algo que se parece al del sujeto en análisis que va a la consulta. Al igual que Sócrates, el sujeto histerizado acude a la consulta en busca de un saber acerca de su sufrimiento, motivado por la idea de que dicho saber lo calmará. Así pues, la condición de posibilidad de la transferencia es que hay un saber en juego, un saber que el sujeto presupone al analista, al igual que, en el diálogo socrático, hay un saber que Sócrates presupone al interlocutor y que extrae por medio de la anamnesis en la dialéctica. Hay una diferencia, y es que en el análisis se privilegia la asociación libre mientras que en el diálogo socrático, el discurso

\section{Platón: Fedro 246 a.}

43. Platón: Fedro 247 b.

44. Posteriormente, Jacques Lacan dirá de Sócrates que fue el primer histérico, por el tipo de discurso que utilizaba, que consistía en preguntar a los otros por su supuesto saber, buscando un maestro del que extraer el saber y al que, en dicha extracción, tender su trampa de la ignorancia. 45. Platón.: El Banquete, Alianza Editorial, Madrid, 2013.

Thémata. Revista de Filosofía $\mathrm{N}^{\circ} 55$ (2017) pp.: 287-302. 
relevante es un diálogo razonado, de carácter lógico y deductivo. Una cierta ironía semejante a la socrática baña también el análisis, ya que el sujeto que se queja de su sufrimiento sabe que, en el fondo, el saber del otro sobre su sufrimiento roza el límite de la impostura, pero aun así, siempre hay un resquicio de saber supuesto al otro y eso mantiene la transferencia a flote.

El diálogo que tienen Zoe y Norbert no dista mucho del diálogo platónico ni del diálogo amoroso del analizante con el analista. Un encuentro similar atraviesa estas tres situaciones, que están presentes en tres contextos muy diferentes: el de la Alemania de principios del siglo XX, el de la Grecia clásica y el que se repite en distintas ocasiones desde principios del siglo XX en Viena hasta hoy. Se trata del encuentro entre dos personas, una de ellas sufre y la otra escucha. Una de ellas atiende la demanda de la otra por medio de la palabra. Una de ellas es ignorante o pretendidamente ignorante y la otra supuestamente conocedora de lo que el otro ignora o de algo que puede aclarar su falta de saber.

Este análisis nos lleva al planteamiento de algunas conclusiones:

El delirio aparece con una doble polaridad: en primer lugar, alcanza una máxima tensión antes de curarse. En segundo lugar, supone también un modo singular de cura desde la perspectiva freudiana: sustituir y desplazar los contenidos censurados por otros derivados de la fantasía supone también un modo de hacer frente a contenidos que algo en el sujeto se resiste a afrontar. El delirio es aquí concebido como sinónimo de un ungüento fabricado por la psique para aliviar el dolor que produciría eso que se censura. En el caso de Norbert, este ungüento se materializa con el olvido de Zoe. Norbert la olvida durante años para luego reencontrarse con ella -y con todo el universo de lo sexual y del deseo reprimido que había vinculado a esa figura- a través de un bajorrelieve, representación de lo muerto, como su deseo, pero en realidad su deseo sólo está dormido y todavía puede desear. Entretanto, el encuentro amoroso surge, como una singular transferencia.

Ambas obras, el original literario y su comentario psicoanalítico, constituyen un punto de partida para repensar algunas preguntas hermenéuticas cruciales como lo son, la cuestión de cómo leer un texto, de cómo darle sentido o de cómo elaborar una interpretación de dicho texto. El diálogo abierto entre poesía y psicoanálisis constituye una fuente de riquezas para seguir explorando el ámbito de la producción artística. Asimismo, las obras de arte poseen, así se lo concede Freud, un carácter abierto a toda interpretación y son per se irreductibles a una visión unita- 
ria. La lectura que hace Freud de las producciones literarias y entre ellas de la novela de Jensen, sitúa la literatura por encima del psicoanálisis. ${ }^{46}$ El médico vienés la privilegia respecto de su propia interpretación, lo cual supone un posicionamiento determinado respecto del carácter abierto de los textos literarios.

Por último, la novela de Jensen Gradiva, publicada en 1901, es releída por Freud con gran interés. En concreto, su interés se centra en la nueva clínica psicoanalítica, que aborda los síntomas del sujeto con otra mirada, ya no tan atenta al mecanismo que los provoca, sino al sentido que de éstos se desgrana, dándolos a conocer como un conjunto lingüísticamente organizado. ${ }^{47}$ Este discurso antipositivista y algo romántico que reivindica la singularidad de cada sujeto que se dirige al análisis no es el producto de un teórico aislado, sino que encaja perfectamente en el contexto de finales del siglo XIX y principios del XX, siguiendo de cerca los pasos del pensamiento de la sospecha de Nietzsche, muerto en 1900.

Numerosos son los que han defendido la filiación schopenhaueriana de Freud frente a la filosofía de Franz Brentano, quien concibe lo psíquico en sintonía con la conciencia y niega la posibilidad de estados psíquicos inconscientes ${ }^{48}$. El inconsciente encuentra puntos en común con el concepto de voluntad ${ }^{49}$ y con el inconsciente de Eduard von Hartmann, quien, influido por Schopenhauer y Hegel, elabora un concepto de inconsciente en el ámbito de la estética filosófica ${ }^{50}$.

Freud elabora su teoría del inconsciente en contraposición a la teoría de una psique que se corresponde con la conciencia. Y Schopen-

46. Freud, S.: El delirio y los sueños en la "Gradiva» de Jensen, Op. cit., p. 37.

47. En Fonction et champ de la parole et du langage, Lacan interpreta a este primer Freud como un autor para quien el inconsciente está estructurado como un lenguaje. De este modo, Lacan lo asume enmarcándolo en un paradigma estructuralista y saussuriano avant-la-lettre. Más tarde, Jacques-Alain Miller sostiene que tanto en Lacan como en Freud hay un primer tiempo donde el inconsciente es simbólico y por tanto deudor del campo del lenguaje y un segundo tiempo en que el inconsciente es más real y se sitúa del lado de lo que excede la lógica del sentido, in Miller, J.A.: Seminario «L'Être et l’Un ", Curso n 6, Lección del 9 de marzo de 2011. Inédito.

48. Brentano, F.: Psychology from an Empirical Standpoint, (1874) Trans. A. C. Rancurello, D. B. Terrell and L. L. McAlister. London: Routledge and Kegan Paul, 1973.

49. Schopenhauer, A.: El mundo como voluntad y representación, Introducción de E. Friedrich Sauer. Editorial Porrúa, México, 1987.

50. Hartmann, Eduard von.: Filosofía de lo Bello: Una reflexión sobre lo Inconsciente en el Arte, Universitat de Valencia, Servei de Publicacions, 2002.

Thémata. Revista de Filosofía $\mathrm{N}^{\circ} 55$ (2017) pp.: 287-302. 
hauer, Wagner y Nietzsche están en el aire mientras Freud estructura su teoría psicoanalítica. Herzog dirá:

Freud tenía pleno conocimiento de una tradición filosófica, centrada en Alemania, que había puesto gran énfasis en el concepto de un inconsciente psíquico... a pesar de su insistencia en que no había leído a Nietzsche ni a Schopenhauer hasta después de haber hecho sus propios descubrimientos. ${ }^{51}$

Cuando era estudiante, Freud perteneció al grupo Leseverein der deutschen Studenten Wiens, (Sociedad de lectores de los estudiantes alemanes de Viena) donde los citados Wagner, Nietzsche y Schopenhauer eran una referencia mayor.

$\mathrm{Al}$ reivindicar la singularidad de cada sujeto, Freud vuelve a conectar con esa doble significación, con la ambivalencia instalada en el término de humano y que al comienzo citábamos: por una parte, lo humano quiere ser universal y extenderse a un conjunto muy numeroso. Dicho conjunto distinguiría, es decir, discriminaría, entre los que son humanos y los que no. Por otra parte, el apelativo humano acentúa lo singular, lo que se escapa del conjunto y destaca por su original forma o ejecución. En esta segunda parte parece haber cabida para lo que limita con lo humano y ya no pertenece, de singular que es, a su conjunto. Este último sentido parece coincidir con el germen antipositivista que Freud, junto a los demás autores citados, cultiva en algún momento a lo largo de su teoría. Freud considera que el texto literario dice más que el texto académico y científico y asevera así su interés por la singular ejecución de las cosas, incluso a la hora de ver lo general con mayor lucidez. De este modo, la búsqueda de sentido juega con los límites de la razón. Quizás es más fácil pasar por la ficción para silenciar mejor a lo monstruoso.

51. Herzog, P.: «The myth of Freud as anti-philosopher» in Freud: Appraisals and Reappraisals, Vol. II, (1988) pp. 163-190. New Jersey: The Analytic Press, p. 169. 


\section{Bibliografía}

Brentano, F.: Psychology from an Empirical Standpoint, (1874) Trans. A. C. Rancurello, D. B. Terrell and L. L. McAlister. London: Routledge and Kegan Paul, 1973.

Carroll, L.: Silvia y Bruno, AKAL, 2013, traducción de Axel Alonso Valle.

Freud, S.: "La interpretación de los sueños» (primera y segunda parte), Obras Completas, vol. 4 y 5, Buenos Aires-Madrid, Amorrortu Editores, 2007-2010.

Freud, S.: «El delirio y los sueños en la "Gradiva» de W. Jensen y otras obras» (1906-1908), Obras Completas, vol. 9, Buenos Aires-Madrid, Amorrortu Editores, 2007.

Freud, S.: «Más allá del principio de placer, Psicología de las masas y análisis del yo, y otras obras», Obras Completas, vol. 18 (1920-1922) Amorrortu Editores, Madrid, 2008.

Hartmann, Eduard von.: Filosofía de lo Bello: Una reflexión sobre lo Inconsciente en el Arte, Universitat de Valencia, Servei de Publicacions, 2002.

Herzog, P.: «The myth of Freud as anti-philosopher» in Freud:

Appraisals and Reappraisals, Vol. II, (1988) pp. 163-190. New Jersey: The Analytic Press.

Lacan, J.: «Fonction et champ de la parole et du langage», in Écrits I, Paris : Seuil, 1966, pp. 235-321.

Lacan, J.: «Lituraterre», in Littérature, $n^{\circ}$ 3, Paris, Larousse, 1971.

Miller, J.A.: Seminario, "L'Être et l’Un », Curso n 6, Lección del 9 de marzo de 2011. Inédito.

Nietzsche, F.: Le gai savoir, Folio Essais, 1982, traducido del alemán por Pierre Klossowski.

Nietzsche, F.: La gaya ciencia, AKAL, 2001.

Platón.: El Banquete, Alianza Editorial, Madrid, 2013.

Platón.: Fedro, Alianza Editorial, Madrid, 2009.

Schopenhauer, A.: El mundo como voluntad y representación, Introducción de E. Friedrich Sauer. Editorial Porrúa, México, 1987.

Schreber, P.: Memorias de un enfermo de nervios, Sexto Piso, 2008. 